\title{
Economic Turbulence and EaaS Grid Computing
}

\author{
JosephNg, P.S. \\ Faculty of Information Technology, Inti International University \\ Persiaran Perdana BBN Putra Nilai, 71800 Nilai, Negeri Sembilan, Malaysia \\ joseph.ng@newinti.edu.my
}

\begin{abstract}
Market turbulence with fiscal investment influences has altered IT infrastructure performance as business pursue extravagant new technology adoption. Yet, few studies have examined how shareware solution goes beyond Medium Size Enterprise that pushes efficiency and sustainability. This PLS-SEM integrated with dual primary compilation approach lessens shallow perceptions coupled with outlooks that streamline each phenomenal activity that is worthy of the necessity for competitive innovation. This unified model was applied to sampling respondents and analyzed using an ordinal regression relationship that generates a robust association that triggers the hypothesis acceptance. The adopting of BOINC shareware mesh network towards unified processing designs that were employed to build the yield by promising financial possibility using coordinated interworks hence improved group accomplishment and establishing greater esteem. This paper showcases a flexible inner IT infrastructure alongside the economic uncertainty with the framework advancement for Exostructure as a Service. Associated theoretical and practical implications were discussed.
\end{abstract}

Keywords: BOINC; cloud computing; economic uncertainty; framework; grid computing; optimization; resource pooling; Small and Medium-Sized Enterprise; technology acceptance model; virtualization 


\section{Introduction}

"Medium Size Enterprise (MSE)" in Malaysia stood predominant player towards contributing 22.3\% of "Gross Domestic Product (GDP)" improvement with $32.8 \%$ of work opportunity (SMECorp, 2020). Being stuck amid the uneconomic feasibility of "Small and Micro Enterprise (SME)" and the greater supremacy "Multi-National Corporation (MNC)", has forced the MSE to in huge dilemma. The huge argument rises out of the obligation of a MSE, even though it only shared $4 \%$ of domestic commercial sectors, the MSE made roughly RM1.2 billion for local's GDP in 2019 (SMECorp, 2020). These businesses predominantly will preserve trying to battle with a greater organization, and they are moreover hesitant or mismatched to put funds into the enhancement investment and reviews new headway. This is a consequence of the attraction of quantity volume discount, profitability, knowledge experience or skillset. Nonetheless, MSE from other Asia Pacific countries that have accepted advancement be-front has now capitalized on their change benefits when appeared differently concerning the investment that was not getting development previously (Guo, 2019, Rao2019). Jung et al. (2018) have included that "undertaking capacities, breaking point and industry progression will decrease the likelihood of frustration". Information Technology has facilitated innovative organizations towards high-level undertakings to perform using new features with updated execution, versatility and enhancing their wealth (Jung, 2018, Zhang, 2019). This is likewise per the powerful development of the endeavour and industry and undertaking. A venture's IT framework standard that is in incredible surroundings with versatile resources can meet the requirements of a new IT framework activity (Benitez, 2018, Valacich). For MSE to extend domestic and international, the current IT framework highlighted the development and its concerns, particularly in the accompanying lesser developed regions (JosephNg 2019):-

- Growing capital consumption and working costs.

- Unfairly profitability from new framework speculation.

- Unoptimized advancement with business elements.

- Unpredictable, vulnerability and intricacy market condition.

The MSE affected by the single-sided IT movement that focused on the customary fundamental operational methods. As large business mechanizes every action, it has caused IT to structure every one of the extra costs. The MSE is also hushed up in related past manages the maltreatment of establishment organizations and preparing progress considering the unmistakable low business regards rather than more noteworthy multinationals improvement (Banares, 2018). Past investigations have revealed that numerous MSE got burnt their investment into uncharted IT foundation while placing additional weight on investment speculation and unquestionably influenced reasonability (Guo, 2019, Banares, 2018). More current and more perplexing technology were added into the current complex IT framework while leaving more client work area decaying as just another plain input capturing workstation as it were. 
Implementation of an IT system could help the MSE to gather more strategic advantages without much extravagant investment, especially for the MSE. Khan (2016) has cautioned that an organization can lessen about RM4 millions of technology costs if this spending is monitored. Nonetheless, this assessment has shown that basic IT adventures are unoptimized. On the other hand, the vast majority of the organization are expecting to grow their IT adventure more than their previous year expenditure plan.

As the economic turbulence ends up being all the more remarkable anyway tangled and rivalry among organizations has gotten exceptionally opposing (Khan, 2016, Bergman, 2020, Anwar, 2016). The monetary weakness is an insecure financial situation where agreements pay at that particular period is missing or defective for economic recovery. During the fiscal related weakness time span moreover, it makes extra IT spending decision more problematic due to limited pay to help higher working expenses. Notwithstanding, business needs to have more broad information to grasp the assessment of IT structure and responsibility as far as it matters for them in moving and organizing into the perspective of cutting edge business. Besides, the highlight has been more on unadulterated invention evolution, instead of boosting the modernization industry assess redesigning. Mesgari, M. \& Okoli, C. (2019) emphasized that "there is constraint knowledge of the contribution where technology features shapes in moulding management sense-making from innovative IT infrastructure, and how management response contributed in it sense-making" (Mesgari, 2019). Albeit the recommended cost-effective deployment is now being recognized for its relentless revolution, the appropriation of such modernization is typically unheard of in the business landscape.

Exostructure as a Service (EaaS) is a hardware solution yet with a flexible implementation process that is configured from existing in-house IT hardware resources. It combined various physical devices to form a bigger virtual server without the need to invest in additional physical servers and cost (Chauhan, 2018, Clinton, 2018, Garin, 2018, Olson, 2018). This virtual server is located within the enterprises own premise. This permit better supervision manoeuvre and monitor as to relate to outer outsource web hosting service, particularly in interoperability latency (from the external web hosting server to the local manufacturing automation system) and service level priority. Being internal devices likewise implies a more guaranteed security certainty level. As the business climate turns out to be more unique yet cost and time-delicate, the requirement for least external interferences ought to be kept away from however much as could be expected. Henceforth, to accomplish these expected referenced before, the EaaS model is an adaptable arrangement. The virtual worker is a powerful worker that mixes with the environment of enterprise implement. As the enterprises appreciating development, they will consistently grow their tasks accordingly putting more resources into additional processing power. As the desktop innovation improved, technology capacity and capability upgrade so will be the EaaS virtual system. These performance outputs are expanded (or decrease) of the system deliverables is addressing business execution to orchestrate the strength and shortcoming of the system execution with the business scene dynamic show. Whenever required, the virtual systems can be scaled back as indicated by when the business experience a difficult period. This adaptability will assist the business with supporting survivability and helps to keep up barebone speculation cost from the unpredictable business is particularly the ineffectively contributed equipment. 
Finally, there were inadequate articles about the use of grid shareware for the smaller company level, particularly the MSE. Bloem da Silveira et al. (2018) depicted modernization execution as a fundamental instrument to upgrade seriousness and to oversee the company in the acquirement, handling and strengthening of modernization to withstand the plan that should be sustainable with the establishment's vital goal (Bloem, 2018). They focused while innovation advancement as a huge discovery to improve output rate, development is not the solitary choice to enhance the work progression. From these concerns, the challenges contention has generated the accompanying discovery conjecture:-

H1: EaaS optimizes available resources when buying new hardware.

$\mathrm{H} 2$ : EaaS avoids unnecessary additional maintenance when buying new hardware.

H3: EaaS shift the budget allocation paradigm when buying new hardware.

H4: EaaS separates economic turbulence independently when buying new hardware.

Applying the progress of an IT framework, MSEs can have the possibility to lean in the direction of the further prominent business atmosphere that was unfeasible in the past. Bloem et al. (2018) highlighted that enterprise ought to "invest in information technology that permits the enterprise to generate extra data without overburdening the technological barriers". Such expansion or adjustment in the IT element across the time frame been mixed as should be anticipated business drive activity like manufacturing automation has forced MSEs to be considerably further ingenious, in this manner opening up their overall appeal.

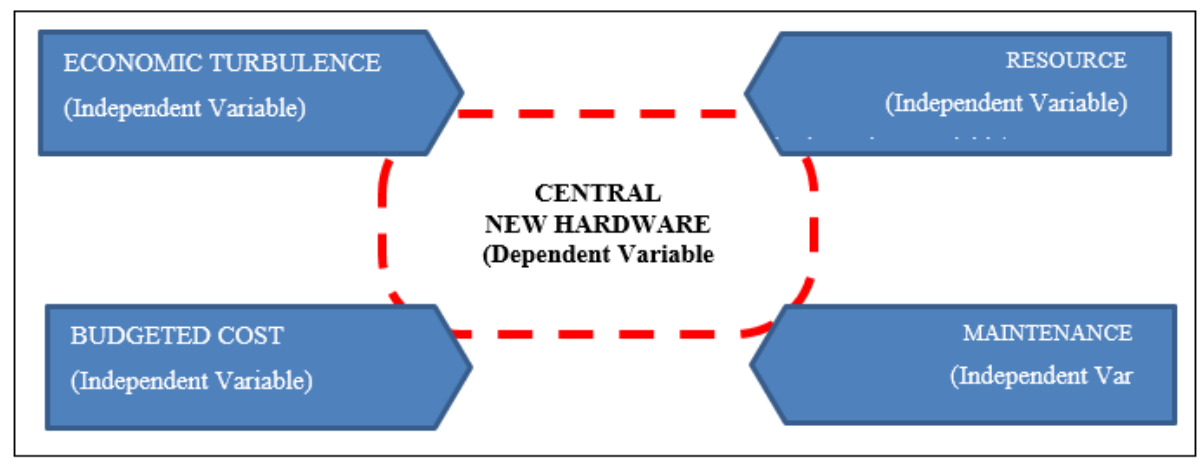

Fig. 1. Research Model

Fig. 1 shows the link between the 4 examination constructs with the principal investigation zone. It furthermore introduces the segments towards the "Dependent Variable" and its linked "Independent Variable". The data will be examined employing "Regression Analysis" from "Model Fitting" merit with "Goodness of Fit" optimistic "Chi-Square" separation for addressing model respondent.

The investigation draws a different methodology viewpoint that may be fundamental to determine the complicated MSE that provoked issues on monetary requirements, incredible unique economic turbulence, evaluating limited assets of recruiting skilful 
abilities and gigantic expense cognizant continuous support. This examination starts relating to the fresh discoveries using three recording instruments ("Quantitative, Qualitative and Delphi"). The re-examined procedure proposed for MSE outline advancement can equally be traced within "Multi-National Corporation" towards a relationship idea outline. At last, this review's discussion created a reasonable negotiating forethought advancement spotting similarities within the "Medium Size Enterprise" to expand its present contribution framework towards an adaptable yet inherent long haul recovery.

\section{Technology Model and Industry Direction}

Within noticeable and basic technology concepts received to comprehend the appropriation and use of innovation incorporates in "Technology Acceptance Model" (TAM) (Wang, 2017). The models, be that as it may, are not without constraints. TAM attested that the real use is identified with a person's demeanour towards utilizing innovation and the model recognized two remarkable determinants of the framework is "Perceived Usefulness (PU)" with "Perceived Ease of Use (PEOU)" (Davis, 1989). Initially, the "Technology Acceptance Model" transpired development towards clarifying the person's appropriation of an electronic mail framework in an enterprise setting. However, the reception depended on work purposes with the silo staff from the enterprise. As such the expense is regularly carried by the enterprise with the reception compulsory. Additionally, Tsai and LaRose (2015) focused on that user ought to have adequate information and aptitudes to utilize new technology when contrasted with workers in an enterprise where preparing and specialized help are given.

Ooi (2016) stressed that TAM trialability and recognizability in their unique structure are not valuable while anticipating another IT/IS selection, all the more so for the Medium Size Enterprise condition. They clarified that since the innovation presently cannot seem to arrive at mass wide nor narrow depth, most of the enterprises would not have the option to test the innovation and hence TAM is not appropriate. As the vast majority of the ordinary systems in MSE has likewise constrained capacity to clarify the appropriation of new advances, this has expanded and altered the TAM with new requirements. The methodology assists in expanding the difference clarified and arguing for TAM adequacy. Thus again, TAM is not fit to be embraced in MSE.

Advancement in the IT infrastructure has pushed the needs for Anything-as-a-Service. This statement precedes the development of a unique feature around the shared facility in Fig. 2 called Exostructure as a Service (EaaS) from the currently available "Software as a Service (SaaS), Platform as a Service (PaaS) and Infrastructure as a Service (IaaS)". MSE typically operated in a single Local Area Network (LAN) environment. Before the MSE moves into the multi-location, including multi-country, they must first build their foundation, locally at the heart of their core head office. They must test and optimize their resources before expanding out, testing it at the LAN grid before expanding into the cloud computing grid. 


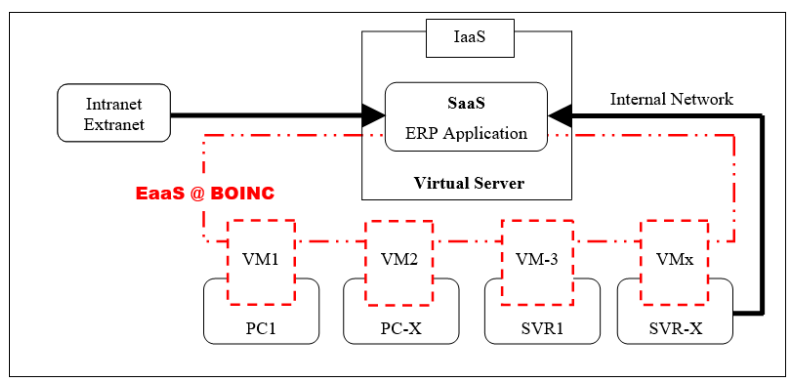

Fig. 2. EaaS Architecture Using BOINC

The architecture in Fig 2 is an integration of Grid Computing and Virtualization deployed back into the "Local Area Network (LAN)". Each enterprise has many existing desktops that they used for daily operations. The "Berkeley Open Infrastructure for Network Computing (BOINC) is an open-source middleware system for volunteer computing and grid computing" (Anderson 2018, 2020). Each desktop is then be installed with an additional BOINC client application. One of the (higher-end) desktops is selected as the BOINC controller that will manage the other BOINC client desktops. The "centralized virtual server" is created from the internal incorporation of multiple lesser-used personal computer, servers or related computing devices inside the enterprise establishing a platform on "Infrastructure as a Service (IaaS)". A second "centralized server" created from a desktop (if available resources from a more redundant desktop) as a backup server. The IaaS is used to distribute the necessary "Software as a Service (SaaS)" tools across the perform for the "Enterprises Resource Planning (ERP)" application to maximize work processes productivities.

Typically, each user inside the Medium Size Enterprises is allocated a dedicated desktop. Due to work process activities convenience and data privacy, these desktops are normally not shared or used by other users. This created an environment of unproductive utilization of each desktop and increasing its operating cost. The BOINC is a shareware solution that is used on the existing desktop without comprising the desktop's performance capabilities and capacities while still able to operate without much-specialized skills needed (Anderson 2018, 2020). Furthermore, as BOINC is installed in a normal $\mathrm{PC}$, it does not require high expensive maintenance as compared to physical servers. To date, BOINC has been installed in numerous hosts without the need to invest in the new separated physical server, nor does it need highly skilled manpower and data centre facilities. Therefore, BOINC role is to minimise further spending on IT infrastructure but yet it can still fulfil the need for a (virtual) server. Furthermore, with the growing popularity of using BONIC from the research centre into industry usage, the need to commercialize it become a significant factor to push for cost-effective solutions.

Top management consistently stresses the essential principles of innovation separation and where the company can use IT to expand competitively. Numerous ventures have even expected to computerise their approaches by exploiting IT (Jahantigh, 2019). Customary accentuations such as reasoning trusts via the assumption that the IT outline has tremendous powers and exceptionality that can influence the business vital directions. 
However, untapped competition should not be special strength or opportunities in every situation apart from all the more substantially, being scant is the vital element. For a huge fragment of situation, fundamental IT resources have resulted up remaining quickly open and reasonably expected. IT has evolved toward gaining largely an overhead of digitized climate that should be compensated by all investment yet gave no differentiation where the excessive assumption does not warrant vital added competitiveness.

Urbach, N. and Ahlemann, F. (2016) repeated that "entire enterprise models and the relentless presence of big business are reliant upon the consistency, availability, adaptability of IT framework" where MSE could convey as an instrument to do a vital response to receptive protection among the business. Alternately, dwelling mindful of innovation can be a valuable decision in the viewpoint of MSEs financial scarcity. Along these lines, MSEs have to make a few exchange-offs in the focus of setting the truly radical latest development with synchronizing with the fiscal venture to pick up competitiveness.

Narayanan (2019) proposed that "enterprise can accomplish sensible differentiation by introducing new highlights that profoundly diminish costs while skilfully offering the benefit and highlights clients prerequisite" within a sensible technology growth. Establishing the latest characteristics carelessly includes higher exceptional offering to take advantage of the possibilities whilst establishing advanced features unable to produce sizeable distinctiveness to progress appeal. "The realisation of an enterprise be subject on its capacity to the advanced improvement of the development swings to upset in their venture models and eventually to enterprise exceptionally" is an awakening call.

Whilst fiscally and information requirements are a well-known concern in smaller enterprise, in whichever situation, it could be unnecessary their fundamental aspects to swear off placing reasonable features as limiting IT framework turns out to be more developed (Benitez, 2018, Valacich, 2018). Besides, fusing IT framework around enterprise automation task practice will just establish apparent outcome after a completely implementation after, previous traditional management main anxiety skewed expectation (JosephNg, 2019, Venkatesh, 2016). Henceforth, the IT foundation is a "protracted at this point continuous capital investment" all across the advancing period structure and possibly dragged towards the volatile commercial season structure moreover.

From the difficulties pushed, this has affected the MSEs establishment approaching plans. Even though web innovation has created with much solidness, the present money related weakness gave extended squeezing variable and unconventionality around the enterprises. System business outcomes frame has contracted to a more unassuming period, convincing judgment choices were impressively more jumbled. With the rising industry peer constrained, various business, while hesitantly, have wasted absurdly in IT establishment, affecting their commercial cash related results (JosephNg, 2012-2021, Venkatesh, 2016, Zhang, 2019). These unsuitable headway divergence, while conceptually brings contemplates, were erratic to their movement were swept under floor covering. The product of the IT system has caused development to remember an exceptional portrayal subordinate to various commercial condition. While moving towards shared office seems, by all accounts, to be enabled, in any case, the more applicable centres should not focus on restricting shared help utilizing electronic yet on redesigning in-house shared office as the elective choice. 


\section{$3 \quad$ Methodology}

The two-fold combination review style concept whereby a two-fold PLS-SEM quantitative and two-fold qualitative is being applied. The assessment-reassessment style provides more predictable investigations were conducted from separate essential information gathered. From the exploration queries referenced already, the discussion had fostered several substantial findings for the discussion inside the review.

Finding and discussion centre to complement and underline framework organization, positioning basic infrastructure, adventures and making towards the on-call request. Each point of queries reviewed will clarify the exploration doubts and aid the essential EaaS outline turn of events and reception. Essential information finding through this review was discussed to comprehend the exceptional advancement of the investigation (Zhang, 2019, Lin, 2018, Creswell, 2018). While the quantitative information distinguishes anomaly of the situation, the examination circles back to subjective information for trademark translation as summaries in Table 1. The records compiled is then evaluated using the "Statistical Package for Social Science (SPSS)" that is shown in Table II, III, IV and Table V.

Table I. Research Methodology Summary

\begin{tabular}{|c|c|c|c|c|}
\hline $\begin{array}{l}\text { Activity / } \\
\text { Phase }\end{array}$ & $\begin{array}{l}\text { Phase } 1 \\
\text { Quantitative } \\
\text { Generalization }\end{array}$ & $\begin{array}{l}\text { Phase } 2 \\
\text { Qualitative } \\
\text { Reasoning }\end{array}$ & $\begin{array}{l}\text { Phase } 3 \\
\text { Testing }\end{array}$ & $\begin{array}{l}\text { Phase } 4 \\
\text { Validation }\end{array}$ \\
\hline $\begin{array}{l}\text { Research } \\
\text { Dimension }\end{array}$ & \multicolumn{4}{|c|}{ Phenomena Explanatory Sequential Dimension } \\
\hline Research Design & $\begin{array}{l}\text { - Dual session Random } \\
\text { Survey }\end{array}$ & - Personal Interview & $\begin{array}{l}\text { - Focus Group } \\
\text { Discussion } \\
\text { Technical Level }\end{array}$ & $\begin{array}{l}\text { - Focus Group } \\
\text { Discussion } \\
\text { Strategic Level }\end{array}$ \\
\hline $\begin{array}{l}\text { Data } \\
\text { Collection }\end{array}$ & $\begin{array}{l}\text { - End users - Managerial } \\
\text { level. } \\
\text { - Peninsular Malaysia. } \\
\text { - } 228 \text { respondents. }\end{array}$ & $\begin{array}{l}\text { - End users - Top } \\
\text { management level. } \\
\text { - Central Malaysia. } \\
\text { - } 10 \text { respondents. }\end{array}$ & $\begin{array}{l}\text { - Consultants, vendors \& } \\
\text { end-users. } \\
\text { - Central Malaysia. } \\
\text { - } 10 \text { respondents. }\end{array}$ & $\begin{array}{l}\text { - Industry Association. } \\
\text { - Central Malaysia. } \\
\text { - } 10 \text { respondents. }\end{array}$ \\
\hline $\begin{array}{l}\text { Research } \\
\text { Methods }\end{array}$ & $\begin{array}{l}\text { - Convenient sampling } \\
\text { using available } \\
\text { organization hosting } \\
\text { final year industrial } \\
\text { training students. }\end{array}$ & $\begin{array}{l}\text { - Convenient sampling } \\
\text { who are willing to } \\
\text { participate and share } \\
\text { information. }\end{array}$ & $\begin{array}{l}\text { - Convenient sampling } \\
\text { who are willing to } \\
\text { participate and share } \\
\text { information. }\end{array}$ & $\begin{array}{l}\text { - Convenient sampling } \\
\text { who are willing to } \\
\text { participate and share } \\
\text { information. }\end{array}$ \\
\hline Data Analysis & $\begin{array}{l}\text { Spearman Correlation } \\
\text { Quantitative Exploration }\end{array}$ & $\begin{array}{l}\text { Qualitative Reasoning } \\
\text { Explanation }\end{array}$ & $\begin{array}{l}\text { Delphi Inductive } \\
\text { Conclusion }\end{array}$ & $\begin{array}{l}\text { Qualitative Reasoning } \\
\text { Explanation }\end{array}$ \\
\hline
\end{tabular}

Great insights has an Alpha worth closer to 1.0 while a lower worth of Alpha demonstrates lower odds of consistency. While the Cronbach Alpha worth of 0.73 in Table II is considered as acceptable (Asad, 2016, Veiga, 2016), this investigation zeroed in additional on the information thinking from both the management interview and expert 
center gathering. Whilst the "Cronbach Alpha" is inside the acceptable reach, this quantitative information filled in as an outliner to the following phase of subjective information thinking.

Table II. Cronbach Alpha

\begin{tabular}{|c|c|}
\hline Cronbach's Alpha & Cronbach's Alpha Based on Standardized Items \\
\hline 0.730 & 0.731 \\
\hline
\end{tabular}

In view of Table III, a huge worth of 0.028 is slighter than 0.05 shows higher acknowledgment of the information for a "Final Model" and in this way the "Independent Value" can anticipate the "Dependent Value" (Kante, 2018, Flowers, 2016). It indicates the "2 Log Likelihood's Final Model" worth of 476.753 is slighter than the benchmark "Intercept Only" worth of 505.241 that help the acknowledgment of the Revised theory. Moreover, the "Chi-Square" worth of 28.488 is a twofold character positive worth that shows the "Final Model" (as a Revised theory) has a critical distinction from utilizing "Intercept Only model" (as Null speculation). Accordingly, the "Initial" theory has been annulled and the Revised hypothesis been set up.

Table III. Model Fitting

\begin{tabular}{|l|r|r|r|r|}
\hline Model & -2 Log Likelihood & Chi-Square & df & Sig. \\
\hline Intercept Only & 505.241 & & & \\
Final & 476.753 & 28.488 & 16 & .028 \\
\hline
\end{tabular}

In view of Table IV, the "significant value" beginnings from 0 (helpless fit) to 1 ("perfect fit") and the bigger the "significant value", the improved the "goodness-of-fit" of the model. Moreover, Udo, E.N. and Akwukwuma, V.V.N. (2019) and Ho, K.L.P. et al. (2018) underscore that a decent model creates higher "significant value". Here, it shows 0.786 where the example can fit $78.6 \%$ of the populace with both the noticed and anticipated that value should be something similar at 484 . This outcome additionally demonstrates the pertinence of growing this investigation to be a pragmatic model for industry commitment.

Table IV. Goodness of Fit

\begin{tabular}{|l|r|r|r|}
\hline & \multicolumn{1}{|c|}{ Chi-Square } & df & \multicolumn{2}{|c|}{ Sig. } \\
\hline Pearson & 459.068 & 484 & .786 \\
Deviance & 385.682 & 484 & 1.000 \\
\hline
\end{tabular}




\section{$4 \quad$ Results and Findings}

Table V shows the relationship between the Dependent Variable (Q12a) with Independent Variables (Q6a, Q10b, Q8c \& Q4c) for the four hypotheses. "Economic Uncertainty" is deemed a "Dependent Variable" while "Budget Cost", "Maintenance", "Product Knowledge" with "Complex Infrastructure" are deemed "Independent Variables".

Table V. Ordinal Regression Case Processing Summary

\begin{tabular}{|c|c|c|}
\hline \multicolumn{2}{|c|}{ TABLE VI. } & $\%$ \\
\hline \multirow{3}{*}{$\begin{array}{c}\text { Eco_Uncertainty - Q12a } \\
\text { (Dependent Variable) }\end{array}$} & Least_Critical & $0.5 \%$ \\
\cline { 2 - 3 } & Slightly Less Critical & $\mathbf{1 2 . 2 \%}$ \\
\cline { 2 - 3 } & Neutral & $\mathbf{2 8 . 4} \%$ \\
\cline { 2 - 3 } & Slighly Critical & $\mathbf{2 7 . 0 \%}$ \\
\cline { 2 - 3 } & Most_Critical & $\mathbf{3 4 . 7 \%}$ \\
\cline { 2 - 3 } & & \\
\hline
\end{tabular}

\begin{tabular}{|c|c|c|}
\hline \multirow{5}{*}{$\begin{array}{l}\text { Budgeted_Cost - Q6a } \\
\text { (Independent Variable) }\end{array}$} & Least_Critical & $1.8 \%$ \\
\hline & Slightly Less Critical & $2.3 \%$ \\
\hline & Neutral & $17.1 \%$ \\
\hline & Slighly Critical & $33.8 \%$ \\
\hline & Most_Critical & $45.0 \%$ \\
\hline \multirow{5}{*}{$\begin{array}{c}\text { Maintenance - Q10b } \\
\text { (Independent Variable) }\end{array}$} & Least_Critical & $1.4 \%$ \\
\hline & Slightly Less Critical & $1.4 \%$ \\
\hline & Neutral & $8.1 \%$ \\
\hline & Slighly Critical & $45.5 \%$ \\
\hline & Most_Critical & $43.7 \%$ \\
\hline \multirow{5}{*}{$\begin{array}{l}\text { Prod_Knowledge - Q8c } \\
\text { (Independent Variable) }\end{array}$} & Least_Critical & $33.6 \%$ \\
\hline & Slightly Less Critical & $28.3 \%$ \\
\hline & Neutral & $22.1 \%$ \\
\hline & Slighly Critical & $10.2 \%$ \\
\hline & Most_Critical & $1.8 \%$ \\
\hline \multirow{5}{*}{$\begin{array}{l}\text { Complex_Infrastructure - Q4c } \\
\text { (Independent Variable) }\end{array}$} & Least_Critical & $0.9 \%$ \\
\hline & Slightly Less Critical & $5.0 \%$ \\
\hline & Neutral & $9.0 \%$ \\
\hline & Slighly Critical & $25.7 \%$ \\
\hline & Most_Critical & $59.5 \%$ \\
\hline
\end{tabular}

While Budget Cost is considered the Most Critical item at $45.0 \%$ in this study due to the traditional limitation associated with the smaller enterprise, Economic Uncertainty at $61.9 \%(34.7+27)$ should not be underestimated due to emerging environmental challenges. While having a complex infrastructure at $85.2 \%$ is critical to tap new technology innovation, it seems to be non-critical at $61.9 \%(33.6+28.3)$ for Product Knowledge. Furthermore, Medium Size Enterprise are very concerned about the ability to maintain these Complex Infrastructures due to the criticalness at $89.2 \%(43.7+45.5)$. In Table VI, the overall Correlation Coefficient r-value is below 0.25 , showing a "Very Weak Relationship" between all the variables. The overall significant $p$ values are also below 0.05 , signalling that the original null hypothesis can be rejected that leads to the acceptance of the revised hypothesis. 
Table V. Independent Variable Bivariate Spearman Correlation

\begin{tabular}{|c|c|c|c|c|c|c|}
\hline & & & Budgeted_Cost & $\begin{array}{l}\text { Complex Infix } \\
\text { astructure }\end{array}$ & Maintenance & $\begin{array}{c}\text { Prod_Knowle } \\
\text { dge }\end{array}$ \\
\hline \multirow{8}{*}{$\begin{array}{l}\text { Spearman's } \\
\text { rho }\end{array}$} & \multirow{2}{*}{ Budgeted_Cost (Q6a) } & Correlation Coefficient & 1.000 & .243 & .838 & .218 \\
\hline & & Sig. (2-tailed) & & -.001 & .001 & -.002 \\
\hline & \multirow{2}{*}{ Complex_Infrastructure (Q10b) } & Correlation Coefficient & .243 & 1.000 & .221 & 209 \\
\hline & & Sig. (2-tailed) & -.001 & & .001 & .001 \\
\hline & \multirow{2}{*}{ Maintenance (Q8c) } & Correlation Coefficient & .838 & .221 & 1.000 & .243 \\
\hline & & Sig. (2-tailed) & .001 & .001 & & .001 \\
\hline & \multirow{2}{*}{ Prod_Knowledge (Q4c) } & Correlation Coefficient & 218 & .209 & .243 & 1.000 \\
\hline & & Sig. (2-tailed) & -.002 & .001 & .001 & \\
\hline
\end{tabular}

While it has been traditionally linked that with a limited budget in the Medium Size Enterprise, it harder to implement much more complex infrastructure that comes with more advanced features. However, with a coefficient value of 0.243 , it shows that on the ground, Medium Size Enterprise is not facing any major difficulties. Data from the management interviews shows that enterprises are utilizing freeware solution to achieved digital transformation without having to invest heavily in their infrastructure. The technical expert from the Delphi focus group has also reaffirmed that the enterprise has already matured towards the implementation of innovative equipment hooked on their everyday standard operating procedures. These mixed-mode data from the quantitative survey, qualitative interview and qualitative focus group iteration have validated the consistency of findings. While this relationship is very weak, it shows positive implications to the enterprise from a technology acceptance and optimization level. The scarce resources traditionally associated with Medium Size Enterprise does not hinder the enterprise to skim the benefits of deploying EaaS grid computing features.

The very weak value of 0.221 in Table VI shows a lesser dependency for large maintenance cost associated with utilizing a complex infrastructure for the Medium Size Enterprise and therefore reducing the budgeted cost. As EaaS grid computing reutilized the existing available desktop in the enterprise, it does not require new or additional investment for the sophisticated physical server and thus having a lesser footprint inside the already cramped Medium Size Enterprise. Without the need for a dedicated data centre with its complicated electrical wiring and air conditioning, more available resources (financial) can be utilized for other priority services. Furthermore, EaaS is available as a freeware software solution without expensive yearly software license cost nor annual software maintenance renewal cost. Even when there is a desktop breakdown is inevitable, the cost of repair is insignificantly lower than a full-fledged traditional server. Moreover, replacement spare parts for the desktop component is much easier to be sourced and expertise available in more cost-competitive options.

Other than saving forthright capital venture, "Medium Size Enterprise" can likewise reduce the requirement for exorbitant activity costs in talented item information labour 
to carry out the mind-boggling foundation as demonstrated by the extremely powerless relationship of 0.209. EaaS application is introduced inside the PC and can be designed to auto startup, accordingly lessening any unpredictable upkeep for the client. Most PC support is effectively accessible at extremely minimum assistance charges. Besides, should a PC face any equipment issues, the substitution part is effortlessly sourced and at a low cost. With the progression of the Enterprise Resource Management framework that is upheld by revaluated aptitude, the company today just requires domestic handling and hard-disk on location for continuous nearby assembling robotization.

For the upkeep versus item information, the exceptionally powerless worth of 0.243 featured the base reliance of recruiting costly mastery only for ICT tasks. Being a work area, most end-client can be moved up to become nearby ICT support staff with fundamental preparation gave, following the advancement of internet preparation like YouTube. Online support, if necessary can be favourable to outsources skills to interface with the nearby worker without the requirement for the irritating transportation time and parking costs. EaaS lattice figuring application has been utilized seriously by numerous undertakings, particularly in the expense delicate climate to work with absolute minimum nearby skill.

As the target of the advanced change is to improve efficiencies, EaaS has additionally assisted with decreasing the activity cost as demonstrated in Table V under "Budgeted Cost" versus "Maintenance" at 0.838 . This solid relationship esteem mirrors the lower support cost emerge despite having a complex framework however at a lower spending cost with the lesser talented staff required. With the expense of innovation lowering down, open-source programming acquiring stable and revaluating promptly accessible from domestic and worldwide distantly, this is the correct second to execute the EaaS mesh network. This advances much better innovation highlights adoption and consequently steer the computerized business for the "Medium Size Enterprise", lessening the requirement for measures duplication and bottleneck activities. From Table II. Cronbach Alpha, Table III. Model Fitting and Table IV. Goodness of Fit has validated the reliability of mix mode and multi-data collection in this study. From this study, Table V. Independent Variable Bivariate Spearman Correlation highlighted the challenging issue of scarce resources that requires a much simpler solution. Table V. Independent Variable Bivariate Spearman Correlation shows the relationship between various spending on IT leading to the impact that addresses the economic uncertainty condition. Lastly, the strong positive relation and strong-weak relationship show the impact of economic uncertainty towards the critical processes in gaining competitive advantages. Table VII summarizes the overall findings of the research based on three primary data collection methods as discussed earlier. 
Table VI. Finding Data Analysis Summary

\begin{tabular}{|c|c|c|}
\hline $\begin{array}{l}\text { Managerial Survey } \\
\text { Findings Summary. }\end{array}$ & $\begin{array}{l}\text { Top Management Interview } \\
\text { Findings Summary. }\end{array}$ & $\begin{array}{l}\text { Expert Focus Group } \\
\text { Findings Summary. }\end{array}$ \\
\hline $\begin{array}{l}\text { A1. Continuous spending on } \\
\text { IT infrastructure } \\
\text { investment currently }\end{array}$ & $\begin{array}{l}\text { B1. Current business economic } \\
\text { turbulence has limited } \\
\text { impact on IT investment } \\
\text { decision due to its } \\
\text { medium and long-term } \\
\text { deliverables. }\end{array}$ & $\begin{array}{l}\text { C1. Current economic turbulence } \\
\text { is a seasonal factor that may } \\
\text { be beyond the work scope } \\
\text { of the budgeting process. }\end{array}$ \\
\hline $\begin{array}{l}\text { A2. Current investment for } \\
\text { IT infrastructure is } \\
\text { based on the pressure } \\
\text { from having what } \\
\text { competitor have }\end{array}$ & $\begin{array}{l}\text { B2. Sufficient technologies to } \\
\text { fulfil operational } \\
\text { requirements. }\end{array}$ & $\begin{array}{l}\text { C2. IT infrastructure is medium } \\
\text { and long-term planning } \\
\text { where contribution may be } \\
\text { experienced during or after } \\
\text { the economic turbulence. }\end{array}$ \\
\hline $\begin{array}{l}\text { A3. The technology features } \\
\text { focuses on day to day } \\
\text { electronic business. }\end{array}$ & $\begin{array}{l}\text { B3. Existing IT infrastructures } \\
\text { investments is to provide } \\
\text { the platform to } \\
\text { differentiate the market } \\
\text { player }\end{array}$ & $\begin{array}{l}\text { C3. Technology edge service is a } \\
\text { major differentiation in } \\
\text { technology product } \\
\text { competition. }\end{array}$ \\
\hline $\begin{array}{l}\text { A4. Managements feels that } \\
\text { their enterprise has } \\
\text { over-invested on ICT }\end{array}$ & $\begin{array}{l}\text { B4. Slow migration to virtual } \\
\text { due to security and } \\
\text { capacity concerns on } \\
\text { shared services. }\end{array}$ & $\begin{array}{l}\text { C4. IaaS high baseline charges is } \\
\text { forcing impractical utility } \\
\text { model for lower range users. }\end{array}$ \\
\hline $\begin{array}{l}\text { A5. A technology feature is } \\
\text { highly dynamic and } \\
\text { evolving. }\end{array}$ & $\begin{array}{l}\text { B5. Perceived IT infrastructures } \\
\text { are nowadays considered } \\
\text { as a Utility Tool for day- } \\
\text { to-day } \\
\text { support. }\end{array}$ & $\begin{array}{l}\text { C5. Current market saturation is } \\
\text { forcing competitive pricing } \\
\text { war to attract customers. }\end{array}$ \\
\hline $\begin{array}{l}\text { A6. Lack of existing internal } \\
\text { IT expertise to } \\
\text { implement } \\
\text { technology solution }\end{array}$ & $\begin{array}{l}\text { B6. Focus primarily on core } \\
\text { operation like client } \\
\text { service } \\
\text { manufacturing flow. and }\end{array}$ & $\begin{array}{l}\text { C6. Technology resources are now } \\
\text { more easily available from } \\
\text { outsourcing }\end{array}$ \\
\hline
\end{tabular}

When the company face different commercial phase, every phase may involve distinctive IT foundation prerequisites (Furstenau 2019, Anderson, 2020, 2018). Throughout the optimistic growth of the project, the broadening of prerequisite has been suitably defended however once the project faces financial vulnerabilities while acquiring assets shortages, the project may be obligated to tolerate the elevated bulk fee of maintenance as demonstrated in Fig. 3. 


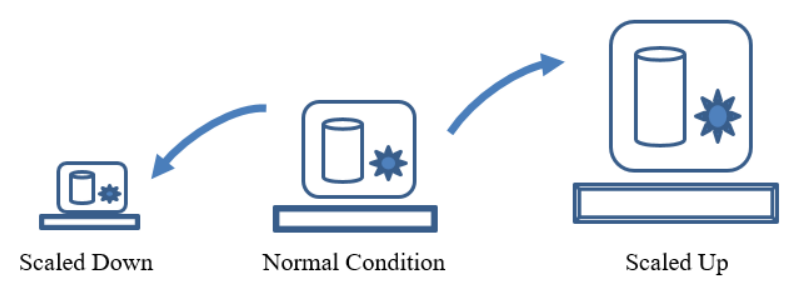

Fig. 3. EaaS Flexible Organic Infrastructure Size Model

The grid computing system in Fig 4 illustrates the way each existing computing's idle disk space and idle CPU can be gathered and enhance as a better-simulated system in a mesh network. While the specification of the desktop increased, so will EaaS platform size growth. Furthermore, when the enterprise expands, it will also expand the capacity of the platform. This produced additional costly funds on investment and generating lower futile activity costly for an undesirable additional tangible system (Anderson, 2018, 2020). Indeed, even the simulated BOINC regulator was made exploiting the present idle personal computer inside the company, subsequently eradicating the necessity for a devoted real server, another expense conserving movement to the resources constraints MSE. While the grid solution is using the existing desktop resources, it, however, does not overburden it. The BOINC controller integration with the desktop operating systems Performance Monitor and Resource Monitor tool will be able to control the critical breakeven point for optimum performance.

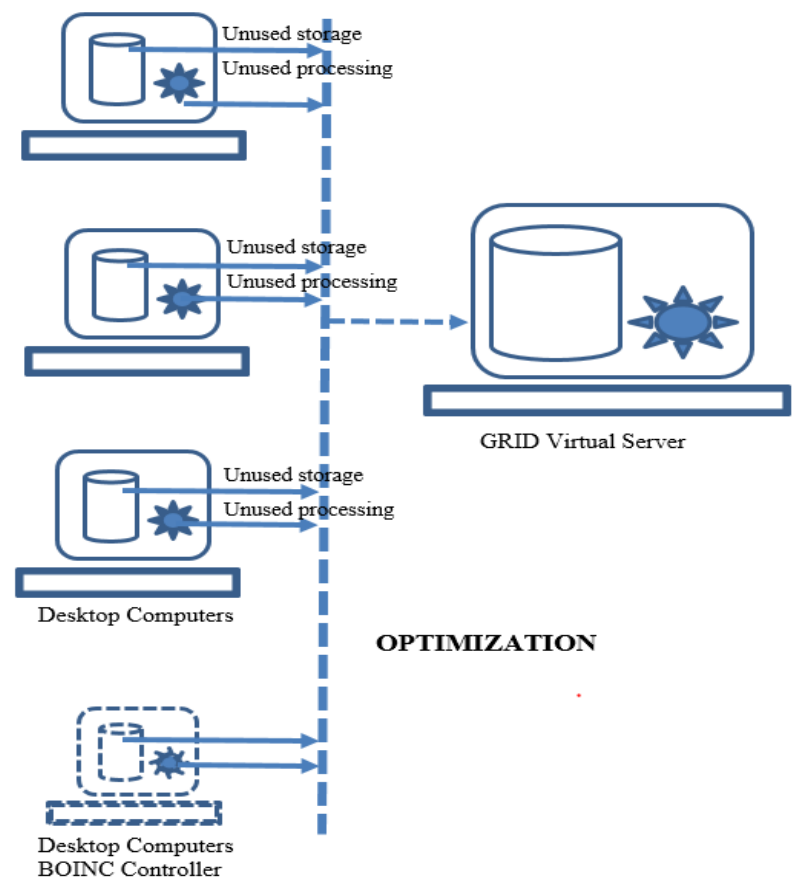

Fig. 4. Optimized Grid Connectivity Using BOINC 
Advancement in IT infrastructure service delivery has pushed the needs for Anythingas-a-Service. This statement leads to the development of a new feature concept around the shared facility in Fig. 4 called Exostructure as a Service (EaaS) from the currently available "Software as a Service (SaaS), Platform as a Service (PaaS) and Infrastructure as a Service (IaaS)". MSE typically operated in a single Local Area Network (LAN) environment. Before the MSE moves into the multi-location, including multicountry, they must first build their foundation, locally at the heart of their core head office. They must test and optimize their resources before expanding out, testing it at the LAN grid before expanding into the cloud computing grid.

The architecture in Fig. 4 is an integration of Grid Computing and Virtualization deployed back into the "Local Area Network (LAN)". Each enterprise has many existing desktops that they used for daily operations. Each desktop is then be installed with an additional BOINC client application. One of the (higher-end) desktops is selected as the BOINC controller that will manage the other BOINC client desktops. The "centralized virtual server" is created from the internal incorporation of multiple lesserused personal computer, laptops or related ICT devices inside the organization establishing a platform on "Infrastructure as a Service (IaaS)". The second "centralized server" if needed, be created from a desktop (if available resources from a more redundant desktop) as a backup server. The IaaS is used to distribute the required "Software as a Service (SaaS)" tools towards executing their "Enterprises Resource Planning (ERP)" application to maximize work processes productivities.

This examination utilizes the BOINC ("Berkeley University Open Infrastructure for Network Computing") open-source matrix arrangement. It energizes a more noteworthy investment in the utilization of innovation without the overpower starting high capital consumption, generally connected with computerization certificate expenses (Chauhan, 2018, Clinton, 2018, Garin, 2018, Olson, 2018). It additionally assists with relieving execution challenges while tending to unstable business and the absence of mastery. BOINC (2016) has been implemented in 56 organization, with 10,139730 clients and 2,015,526 hosts. With open-source, it likewise permits a lot more extensive adaptabilities later on upgrade and least yearly support charges. Every one of the workstations, which could be a commonplace work area or PC is introduced with a focal BOINC controller application. A focal desktop will be utilized to deal with the entire framework arrangement. This desktop can likewise be arranged from a current worker, accordingly bringing down the underlying capital venture. At whatever point the workstation is a startup, the controller desktop will initiate the BOINC application as foundation administrations. It will be pre-arranged to get the grid assignment from the BONIC desktop from the neighbourhood workstation. The desktop will likewise recognize and screen the accessibility or execution abilities and limits of every workstation as the company expand or shrink per the business landscape to determine difficulties looked by the unstable business for synergetic development. The grid assignment is covered at a particular limit of the nearby workstation preparing capacities so as not to trouble the client front-end application handling abilities and twist their exhibitions. 
Typically, each user inside the Medium Size Enterprises is allocated a dedicated desktop. Due to work process activities convenience and data privacy, these desktops are normally not shared or used by other users. This created an environment of unproductive utilization of each desktop and increasing its operating cost. The BOINC is a shareware solution that is used on the existing desktop without comprising the desktop's performance capabilities and capacities while still able to operate without much-specialized skills needed. Furthermore, as BOINC is installed in a normal PC, it does not require high expensive maintenance as compared to physical servers. To date, BOINC has been installed in numerous hosts without the need to invest in the new separated physical server, nor does it need highly skilled manpower and data centre facilities. Therefore, BOINC role is to minimise further spending on IT infrastructure but yet it can still fulfil the need for a (virtual) server. Furthermore, with the growing popularity of using BONIC from the research centre into industry usage, the need to commercialize it become a significant factor to push for cost-effective solutions.

\section{Conclusion \& Limitation}

Studies about grid computing for decades mainly focused on non-commercial concepts. Simultaneously discoveries are additionally uncertain because of the low visibilities of Medium Size Enterprise. The compact economy of scale for such an enterprise group offers limited motivation to continue grid computing research, leading to the natural demise of such a powerful solution. This paper expands the body of knowledge, specifically in the Medium Size Enterprise.

Furthermore, top management reacts indifferently to the returns of investment in information technology. Poor visibilities on the direct contribution of the technology. These lead to the challenges of painting meaningful conclusion in the past and sunrise in the future contribution. The ending of further investment aims to the paradigm shift the mindset that technology is no longer a high capital investment.

The discoveries of this examination featured that albeit new novelty features set up that ineffective of the current PC is a different significant factor of IT foundation adventures. Adding more agony is the effect of monetary vulnerability when productivity is uncertain. Besides, it indicates that an inefficient IT framework arrangement is a basic element of projects with depressing Return on Investment, giving critical impact to over-venture and over-financial plan. With instability, vulnerability, multifaceted nature and similar concerns continue haunting the project, a radically further flexible IT foundation outline has been demanded. The review provokes the proposed organic IT framework frameworks that could inflate or diminish per the business landscape triggering the making towards the "Exostructure as a Service" standard in the innovation administration documentation. BOINC cost-friendly framework processing arrangement has been conveyed toward the principle foundation framework to make another virtualized operation.

Such arrangement intends toward (1) REDUCE superfluous wastage for the company from costly equipment and programming licenses. Besides, it empowered (2) REUSE in the business by offering unified internal technology features without external 
solution dependences. This empowers work coordination and hence incredibly improve group cooperative energy. The reserve funds from more slender capital venture and working costs from (3) RECYCLING a developed and stable answer for expanding investor's abundance. All the more significantly, this examination (4) incite RETHINKING on the utilization of the developed GRID arrangement in the assets that have generally compromise the Medium Size Enterprise.

Importantly, the discussion and interpretation of the outcomes from this analysis offer a novel awakening to the use of internal IT infrastructure beyond traditionally "just follow the crowd" to cloud computing and virtual server. It provides an in-depth analysis of the justification to support the recommendation of deploying a hidden yet available cost-effective and matured GRID solution. All this while, optimization of the desktop was not much of a priority in most enterprise and were keep a low profile as just another typical office automation running Microsoft Office while enterprise focuses on upgrading their servers. It became apparent that there exist little or insignificant interrelationship between the resource constraint of a typical Medium Size Enterprise with the Multi-National Corporation as the core issue lies in the optimization of the IT infrastructure rather than procurement of new IT infrastructure technology features. This study provokes an awakening about the great potential of a matured GRID solution that requires paradigm social mindset changes to appreciate its benefits.

Potential future research could investigate how the BOINC grid can be used in parallel with available commercial virtualization solution. These integrations could ignite a better acceptance rate for open source solution usage within commercial sensitive business systems that require a wider features solution. Future study should explore expanding the vertical depth and horizontal wide of data collection in this current mix mode testretest data collection. More quantitative and qualitative data will then enrich the information to become a better justification that entailed better analytics.

\section{References}

[1] SMECorp (2020), http://www.smecorp.gov.my/images/SMEAR/SM EAR2018_2019/final/english/SME\%20AR\%20\%20English\%2020All\%20Chapter\%20Final\%2024J an2020.pdf, Access on 18/02/2020.

[2] Guo, Z., Li, J. \& Ramesh, R. (2019), Optimal Management of Virtual Infrastructure Under Flexible Cloud Service Agreement, Information Systems Research, 30(4), 1424-1446

[3] Rao J.J., Kumar V. (2019) Technology Adoption in the SME Sector for Promoting Agile Manufacturing Practices. In: Satapathy S., Bhateja V., Das S. (eds) Smart Intelligent Computing and Applications. Smart Innovation, Systems and Technologies, 105. Springer, Singapore

[4] Jung, H., Hwang, J.T. \& Kim, B.K., (2018), Does R\&D investment increase SME survival during a recession?, Technological Forecasting and Social Change, 137(December), 190-198.

[5] Zhang, D. \& Nault, B.R. \& Wei, X. (2019), The strategic value of information technology in setting productive capacity, Information Systems Research, 30(4), 1124-1144

[6] Benitez, J., Ray, G. \& Henseler, J. (2018), Impact of information technology infrastructure flexibility on mergers and acquisitions, MIS Quarterly, March, 25-43

[7] Valacich, J.S., Wang, X. \& Jessup, L.M., (2018), Did I Buy the Wrong Gadget? How the Evaluability of Technology Features Influences Technology Feature Preferences and Subsequent Product Choice, MIS Quarterly, 42(2), 633-644 
[8] Banares, J.A. \& Altmann, J. (2018), Economics behind ICT infrastructure management, Electron Markets, 28(Feb), 7-9.

[9] Khan, Z.H. (2016), Exploring Strategies that IT Leaders Use to Adopt Cloud Computing, Doctor of Business Administration thesis, Walden University

[10] Bergmann, M., Brück, C., Knauer, T., \& Schwering, A. (2020). Digitization of the budgeting process: determinants of the use of business analytics and its effect on satisfaction with the budgeting process. Journal of Management Control, 31(1-2), 25-54.

[11] Anwar, N., Masrek, M.N., Sani, M.K.J. \& Mohamad, A.N., (2016), The proof of concept on the determinants of strategic utilization of information systems, International Information Institute, 19(7A), 27-55

[12] Mesgari, M. \& Okoli, C. (2019), Critical review of organization-technology sensemaking: Towards technology materiality, discovery and action, European Journal of Information Systems, 28(2), 205232

[13] Chauhan, S., Jaiswal, M., Rai, S., Motiwalla, L. \& Pipino, L. (2018), Determinants of adoption for open-source office applications: A plural investigation, Information Systems Management, 35(2), pp. 80-97

[14] Clinton, V. (2018), Savings without sacrifice: a case report on open-source textbook adoption, Open Learning: The journal of open, distance and e-learning, 33(3), pp. 177-189

[15] Garin, A.M., Garcia, J.A.M., Medel, J.M. \& Lizarraga, J.M. (2018), Environmental monitoring system based on an Open Source Platform and Internet of Things for building energy retrofit, Automation in Construction, 87(March), pp. 201-214

[16] Olson, D.L. (2018), Open source ERP business model framework, Robotics and computer integrated manufacturing, 50(April), pp. 30-36

[17] da Silveira B. et al. (2018), Technology Road Mapping: A methodological proposition to refine Delphi results, Technology forecasting \& social changes, 126(2018), 194-206

[18] Wang, I.K. \& Seidle, R., (2017), The degree of technological innovation: A demand heterogeneity perspective, Technological Forecasting and Social Change, 125(December), 166-177

[19] Davis, F. D. (1989), Perceived usefulness, perceived ease of use, and user acceptance of information technology, MIS Quarterly, 13(3), 319-339.

[20] Tsai, H., \& LaRose, R. (2015), Broadband Internet adoption and utilization in the inner city: A comparison of competing theories, Computers in Human Behavior, 51(2015), 344-355

[21] Ooi, K.B. \& Tan, W.H. (2016), Mobile technology acceptance model: An investigation using mobile users to explore smartphone credit card, Expert Systems with Application, 59(2016), 33-46

[22] Anderson, D.P. (2018), BOINC: A platform for volunteer computing, Computer Science, Cornell University Press, 1-37

[23] Anderson, D.P. (2020), BOINC: A platform for volunteer computing, Journal of Grid Computing, 18(1), 99-122

[24] Jahantigh, F. F. (2019), A conceptual framework for business intelligence critical success factors, International Journal of Business Information Systems, 30(1), 109-123.

[25] Urbach, N. \& Ahlemann, F. (2016), Infrastructure as Commodity: IT Infrastructure Services are Traded on Free Markets and Purchased as Required, IT Management in the Digital Age, Springer, 7584

[26] Narayanan, V.K. (2019), Radical cost innovation, Strategy \& Leadership, 47(5), 53-54

[27] Alkhanak, E. N., Lee, S. P., Rezaei, R., \& Parizi, R. M. (2016). Cost optimization approaches for scientific workflow scheduling in the cloud and grid computing: A review, classifications, and open issues. Journal of Systems and Software, 113(March), 1-26.

[28] JosephNg, P.S., Loh, Y.F. \& Eaw, H.C. (2020), Grid Computing for MSE during Volatile Economy, International Conference on Control, Automation and Systems, IEEE Explore, Busan, Korea, 709-714

[29] JosephNg Poh Soon, Kang Chon Moy, Ahmad Kamil Mahmood, Wong See Wan, Phan Koo Yuen, Saw Seow Hui, Lim Jit Theam (2016), EaaS: Available yet Hidden Infrastructure inside MSE, 5th 
International Conference on Network, Communication and Computing, ACM International Conference Proceeding Series, Kyoto, Japan, 17-20.

[30] JosephNg, P.S., Kang, C.M., Choo, P.Y., Wong, S.W., Phan, K.Y. \& Lim, E.H. (2015), Beyond cloud infrastructure services in medium size manufacturing, International Symposium on Mathematical sciences \& Computing Research, Ipoh, Malaysia, 150-155

[31] Ng P.S. Joseph, P.Y. Choo, S.W. Wong, K.Y. Phan, E.H. Lim, (2012), Malaysia SME ICT During Economic Turbulence, International Conference on Information \& Computer Network, Singapore, 6771

[32] J Ng Poh Soon, CP Yin, WS Wan, MSH Nazmudeen (2011), Energizing ICT Infrastructure for Malaysia SME during Economic Turbulence, Student Conference on Research and Development, Cyberjaya, Malaysia, IEEE Explore, 328-322.

[33] JosephNg, P.S. \& Eaw, H.C. (2021), Still Technology Acceptance Model? Reborn: Exostructure as a Service Model, International Journal of Business Information Systems, Forthcoming

[34] JosephNg, P.S. \& Eaw, H.C. (2021), Making financial sense from EaaS for MSE during economic uncertainty, Advances in Intelligent Systems and Computing, 1(2), 976-989

[35] JosephNg, P.S. (2019), EaaS Infrastructure Disruptor for MSE, International Journal of Business Information Systems, 30(3), 373-385.

[36] JosephNg, P.S. (2018), EaaS Optimization: Available yet hidden information technology infrastructure inside medium size enterprises, Journal of Technological Forecasting and Social Change, 132(July), 165-173.

[37] JosephNg Poh Soon and Kang Chon Moy (2016), Beyond barebone cloud infrastructure services: Stumbling competitiveness during economic turbulence, Journal of Science \& Technology, 24(1), 101121

[38] Joseph, N.P.S., Mahmood, A. K., Choo, P.Y., Wong, S.W., Phan, K.Y. and Lim, E. H. (2015) 'Barebone cloud IaaS: Revitalization disruptive technology', International Journal of Business Information System, 18(1), 107-126.

[39] Joseph, N. P. S., Mahmood, A. K., Choo, P. Y., Wong, S. W., Phan, K. Y. \& Lim, E. H. (2014), IaaS Cloud Optimization during Economic Turbulence for Malaysia Small and Medium Enterprise, International Journal of Business Information System, 16(2), 196-208.

[40] Joseph, N. P. S., Mahmood, A. K., Choo, P. Y., Wong, S. W., Phan, K. Y. and Lim, E. H. (2013) 'Battles in volatile information and communication technology landscape: The Malaysia small and medium enterprise case', International Journal of Business Information System, 13(2), 217-234.

[41] JN, P.S.; Kang, C.M.; Mahmood, A.K.; Choo, P.Y.; Wong, S.W.; Phan, K.Y.; \& Lim, E.H. (2016), Exostructure Services for Infrastructure Resources Optimization, Journal of Telecommunication, Electronic \& Computer Engineering, 8(4), 65-69

[42] PS Joseph Ng, PY Choo, SW Wong, KY Phan, EH Lim (2012), Hibernating ICT Infrastructure During Rainy Days, Journal of Emerging Trends in Computing \& Information Sciences, 3(1), 112-116.

[43] Venkatesh, V., Brown, S.A. and Sullivan, Y.W. (2016), Guidelines for Conducting Mixed-methods Research: An Extension and Illustration, Journal of the Association for Information Systems, 17(7), 435-495.

[44] Zhang, K. \& Alasmari, T. (2019), Mobile learning technology acceptance in Saudi Arabian high education: an extended framework and a mixed-method study, Education and Information Technologies, 24(3), 2127-2144

[45] Lin, T.T.C. (2018), Multiscreen Social TV System: A mixed-method understanding of users; attitude and adoption intention, International Journal of Human-Computer Interaction, 35(2), 99-108

[46] Creswell, J.W. (2018), Research Designs: Qualitative, quantitative and mixed methods approach, 5E, Thousand Oaks, Sage publication.

[47] Asad, M., Sharif, M.N.M. \& Alekam, J.M., (2016), Moderating effect of entrepreneurial networking on the relationship between access to finance and performance of micro and small enterprises, paradigms research journal, 10(1), 1-13

[48] Veiga, A.D., (2016), A cybersecurity culture research philosophy and approach to developing a valid and reliable measuring instrument, SAI Computing Conference 2016, July 13-15, London.

[49] Kante, M., Chepken, C. \& Oboko, R. (2018), Effects of Farmers' Peer Influence on the Use of ICT- 
based Farm, Input Information in Developing Countries: A Case in Sikasso, Mali, Journal of Digital Media \& Interaction, 1(1), 99-116

[50] Flowers, E., Freeman, P., Flowers, E. P., Freeman, P., \& Gladwell, V. F. (2016). A cross-sectional study examining predictors of visit frequency to local green space and the impact this has on physical, $B M C, 16(420), 1-8$

[51] Udo, E.N. \& Akwukwuma, V.V.N. (2019), Software adaptability metrics model using ordinary logistic regression, Journal of Software, 14(3), 116-128

[52] Ho, K.L.P., Nguyen, C.N., Adhikari, R., Miles, M.P. \& Bonney, L. (2018), Exploring market orientation, innovation and financial performance in agricultural value chains in emerging economies, Journal of Innovation \& Knowledge, 3(3), 154-163.

[53] Furstenau, D., Baiyere, A. \& Kliewer, N. (2019), A dynamic model of embeddedness in digital infrastructure, Information Systems Research, 30(4), 1319-1342 